\title{
Lyme disease: case report of persistent Lyme disease from Pulaski County, Virginia
}

This article was published in the following Dove Press journal:

International Medical Case Reports Journal

4 December 2013

Number of times this article has been viewed

\author{
James R Palmieri' \\ Scott King \\ Matthew Case' \\ Arben Santo ${ }^{2}$ \\ 'Department of Microbiology, \\ Infectious and Emerging Diseases, \\ ${ }^{2}$ Department of Pathology, Edward \\ Via College of Osteopathic Medicine, \\ Blacksburg, VA, USA
}

\begin{abstract}
A 50-year-old woman from Pulaski, Virginia, presented to a local clinic with headaches, fever, generalized joint pain, excessive thirst and fluid intake, and a progressing rash on her back. On physical examination, she had a large circular red rash on her back with a bull's-eye appearance, $16 \times 18 \mathrm{~cm}$ in diameter. Serologic tests confirmed a diagnosis of Lyme disease. The patient could recall a walk through the woods 3 weeks prior, although she never noticed a tick on her body. Following a prolonged course of antibiotics, this case report presents a patient with ongoing symptoms consistent with post-treatment Lyme disease.

Keywords: arthritis, chronic Lyme disease (CLD), ELISA, erythema migrans, ixodid ticks, Lyme disease, post-treatment Lyme disease syndrome (PTLDS), Western blotting
\end{abstract}

\section{Introduction}

Lyme disease (LD), caused by the spirochete bacteria of the genus Borrelia, is the most common vector-borne infectious disease in North America. More than 38,000 new cases were reported in the US in $2009,{ }^{1}$ but underreporting is estimated to be six- to twelvefold, making the true number likely over 200,000 cases per year. ${ }^{2}$

LD is caused by five species of spirochete bacteria of the genus Borrelia. Borrelia burgdorferi sensu stricto is the main cause of LD in North America, while Borrelia afzelii, Borrelia garinii, B. burgdorferi, Borrelia spielmanii, and Borrelia bavariensis are the cause of most cases of LD in Europe. ${ }^{3}$ LD was named after two towns in ConnecticutLyme and Old Lyme - where the disease was recognized as a separate entity with the investigation of a cluster of children who experienced uncommon arthritic symptoms preceded by a characteristic skin rash during 1975-1976. This rash, termed erythema migrans (EM), had been linked in Europe to the bite of Ixodes ticks. B. burgdorferi was first identified in $1982 .{ }^{4}$ LD manifests itself as a multisystem inflammatory disease that affects the skin in its early, localized stage, and then spreads to the joints, nervous system, heart, and other organ systems in its later disseminated stage. ${ }^{5}$

In the US, LD is transmitted by the bite of vector ticks of the genus Ixodes, primarily by the deer tick Ixodes scapularis. ${ }^{6}$ Ixodid ticks are responsible for transmitting the spirochetes from mammals to humans. Ixodid ticks have a 2-year life span, in which they pass through three developmental stages - larva, nymph, and adult - feeding only once per stage. ${ }^{4}$ Ixodid ticks acquire $B$. burgdorferi by ingesting a blood meal from an animal reservoir like the white-footed mouse (Peromyscus leucopus). ${ }^{2,7,8}$ In more urban areas, the reservoir is more diverse due to host availability, and will include chipmunks, shrews, squirrels, and even birds and lizards. ${ }^{9}$ The tick larvae overwinter 
and emerge the following spring in the nymphal stage, which is the stage of the tick that is most likely to transmit the Borrelia infection. ${ }^{10}$ Nymphs are responsible for $90 \%$ of human disease transmission; nymphal stage ixodid ticks are rarely noticed because of their small size $(<2 \mathrm{~mm}) .{ }^{4,6}$

LD is endemic in North America, Europe, and Asia, and the distribution of the vectors directly affects the incidence of the disease. ${ }^{7}$ Most cases of LD in the US occur in southern New England, southeastern New York, New Jersey, eastern Pennsylvania, eastern Maryland, Delaware, and parts of Minnesota, Wisconsin, and Michigan. ${ }^{10}$ The Centers for Disease Control and Prevention (CDC) National Notifiable Diseases Surveillance System lists LD as a notifiable disease within its summary of notifiable diseases. ${ }^{8}$

The incidence of LD in Virginia has increased almost threefold from 2002 to 2011, with Virginia ranking 15th in the nation for reported LD infections. ${ }^{11} \mathrm{LD}$ is the fastestgrowing vector-borne disease in the US. ${ }^{6}$ This growth is in part due to the geographic spread of zoonotic hosts like the white-tailed deer southward and westward from northern regions of Virginia. ${ }^{11}$ While the white-tailed deer are required for the widespread distribution of the ixodid tick, they are not the most suitable hosts for B. burgdorferi. ${ }^{12}$

\section{Case report}

A 50-year-old Caucasian female presented to the urgent care clinic with extreme headaches, fever with intermittent shivering cold spells, 10/10 generalized joint pain, excessive thirst and fluid intake, and a progressing rash on her back. The patient described the headaches as tremendous pressure pushing inwards "as though she was wearing a heavy helmet," such pressure that sneezing and coughing gave her the perception that her "head would explode."

Three days before her visit to the urgent care clinic (day one), the patient noticed an initial small, slightly raised lesion resembling an insect or spider bite. The patient did not examine her back, but described what she thought to be a scab covering the bite while she scratched. On day two, the patient's fever reached $39.3^{\circ} \mathrm{C}\left(102.8^{\circ} \mathrm{F}\right)$, and she had an increasing burning sensation at the site of the bite. A family member examined the bite, and recognized that the bump had developed into a circular rash. The patient took over the counter ibuprofen and Benadryl, and was able to sleep through the night. On day three, the patient felt poorly, but completed a normal working day. By day four, the patient awoke feeling worse, with 10/10 joint pain, high fever, and excessive thirst and fluid intake; this led her to seek medical attention.

On exam, her temperature was $40.2^{\circ} \mathrm{C}\left(104.4^{\circ} \mathrm{F}\right)$. She had a large circular red rash on her back with bull's-eye appearance, $16 \times 18 \mathrm{~cm}$ in diameter (Figures 1 and 2). The rest of her physical examination was unremarkable. Her prior medical and surgical history is not significant to this case. The patient recalled a walk in the woods 3 weeks prior to her exam, but denied finding a tick on her body.

Initial laboratory investigation results are shown in Tables 1 and 2. The patient's white blood cell count and platelet count, hemoglobin, and hematocrit were within normal ranges. Her serum chemistry was unremarkable, except for elevated glucose, borderline low alkaline phosphatase, and slightly depressed osmolality.

A serologic test for LD (antibody response to B. burgdorferi by enzyme-linked immunosorbent assay [ELISA]) was ordered and showed negative results (Table 3). A 10-day treatment of doxycycline (500 mg twice a day) was prescribed. The patient gradually began feeling better, and was able to return to work after 4 days of antibiotic medication. On day nine, her body temperature was within normal limits, the polydipsia and headaches had dissipated, and the rash had

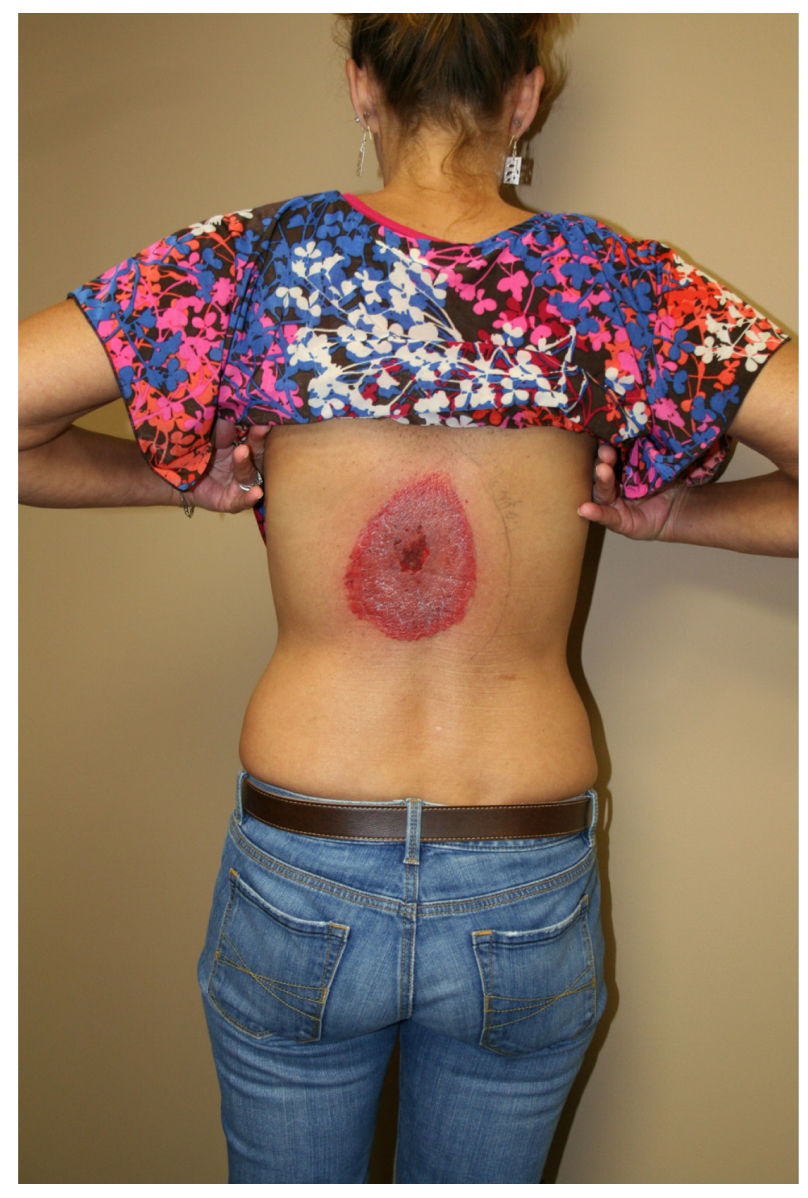

Figure I Back of 50 year old female patient from Southwest Virginia showing erythema migrans "bulls-eye" the characteristic rash of Lyme disease.

Note: The rash had decreased to $11 \mathrm{~cm} \times 14 \mathrm{~cm}$ by day 9 post infection following 4 full days of antibiotic treatment. 


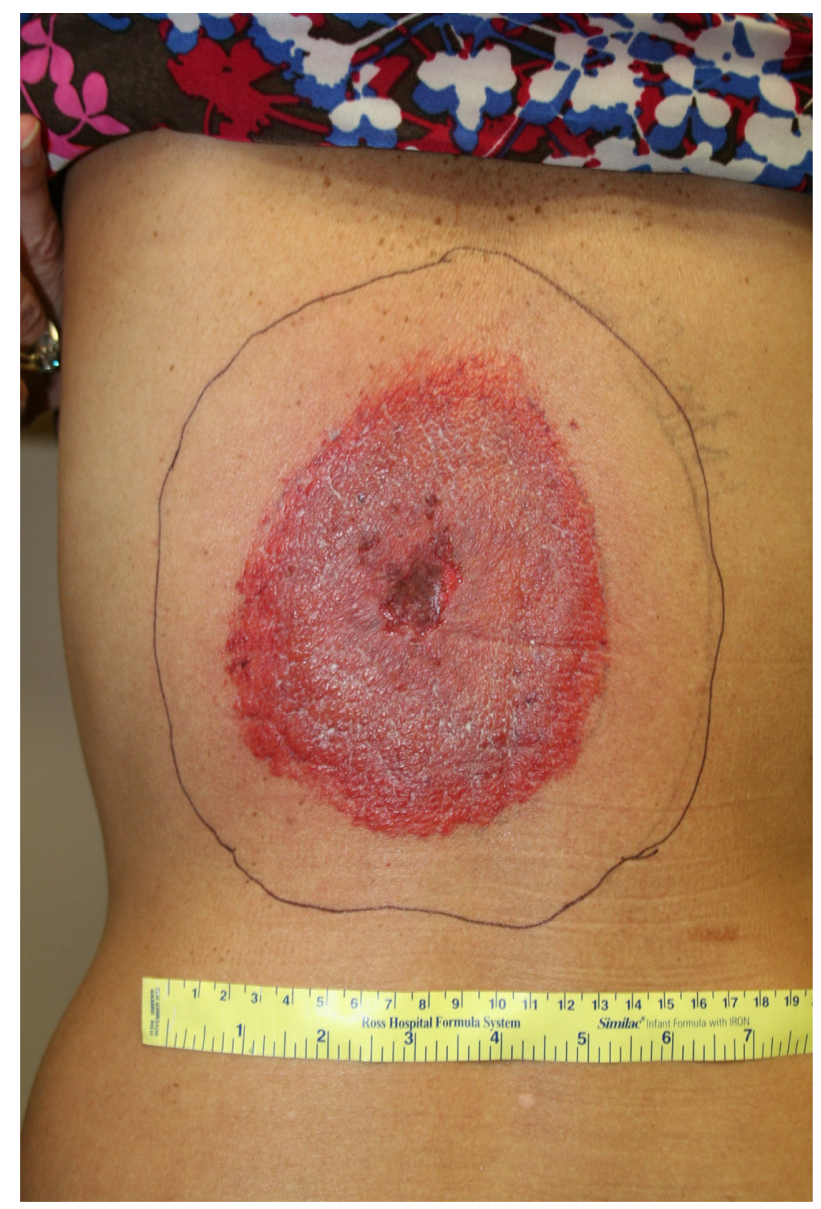

Figure 2 Back of 50 year old female patient from Southwest Virginia showing erythema migrans "bulls-eye" characteristic of Lyme disease.

Note: The rash had decreased from $16 \times 19 \mathrm{~cm}$. (black inked outer oval, pretreatment) to $1 \mathrm{l} \mathrm{cm} \times 14 \mathrm{~cm}$. (bright reddened area, day 4 of treatment).

decreased to $11 \times 14 \mathrm{~cm}$. The patient expressed concern that a 10-day treatment was inadequate in proportion to her symptoms and to the size of her rash. Her doxycycline prescription was extended to 30 days by her primary care physician, continuing at $500 \mathrm{mg}$ twice daily.

A second set of serologic tests were ordered on day 28, which demonstrated the presence of immunoglobulin (Ig)-M without IgG antibodies to B. burgdorferi. The

Table I Results of hematological examination

\begin{tabular}{lll}
\hline Parameter & Admission value & Reference range \\
\hline WBC count, cells $/ \mathrm{mm}^{3}$ & 5,700 & $5,000-10,500$ \\
Segments, \% & 83.5 & $32-75$ \\
Lymphocytes, \% & 10.3 & $21-5 \mathrm{I}$ \\
Eosinophils, \% & 0.2 & $0-10$ \\
Basophils, \% & 0.2 & $0-2$ \\
Immature granulocytes, \% & 0.2 & $0-0.5$ \\
RBC count, million cells $/ \mathrm{mm}^{3}$ & 4.3 & 4.2 to 5.4 \\
Hemoglobin, g/dL & 14.2 & $12-16$ \\
Hematocrit, \% & 40.8 & $36-46$ \\
Platelet count $/ \mathrm{mm}^{3}$ & 139,000 & $130,000-400,000$ \\
\hline
\end{tabular}

Abbreviations: WBC, white blood cell; RBC, red blood cell.
Table 2 Comprehensive metabolic panel

\begin{tabular}{lll}
\hline Parameter & Admission value & Reference range \\
\hline Sodium, mmol/L & 138 & $135-145$ \\
Potassium, mmol/L & 3.9 & $3.5-5.3$ \\
Chloride, mmol/L & 100 & $98-110$ \\
$\mathrm{CO}_{2}, \mathrm{mmol} / \mathrm{L}$ & 23 & $21-31$ \\
Urea nitrogen, $\mathrm{mg} / \mathrm{dL}$ & 8 & $6-20$ \\
Creatinine, $\mathrm{mg} / \mathrm{dL}$ & 0.82 & $0.5-1.2$ \\
Blood glucose, $\mathrm{mg} / \mathrm{dL}$ & $10 \mathrm{I}$ & $70-99$ \\
Total protein, g/dL & 5.8 & $6.0-8.3$ \\
Albumin, g/dL & 4.0 & $3.2-5.5$ \\
Calcium, $\mathrm{mg} / \mathrm{dL}$ & 8.6 & $8.5-10.7$ \\
Total bilirubin, $\mathrm{mg} / \mathrm{dL}$ & 0.4 & $0.3-1.0$ \\
Alkaline phosphatase, $\mathrm{mg} / \mathrm{dL}$ & 40 & $42-121$ \\
AST, IU/L & 15 & $10-42$ \\
ALT, IU/L & 10 & $10-60$ \\
Globulin, g/dL & 1.8 & $1.7-3.9$ \\
Osmolality, mOsm/kg & 270 & $275-301$ \\
\hline Abbrevations &
\end{tabular}

Abbreviations: AST, aspartate aminotransferase; ALT, alanine aminotransferase.

patient also sought a dermatology consultation, and the lesion was biopsied. The pathology report described microscopic changes consistent with lichenoid and spongiotic dermatitis. A Steiner stain failed to reveal spirochetes.

On day 48, 2 weeks after completing the antibiotics, the patient began experiencing lower-extremity neuralgia as well as tingling in her hands. She described her pain as "electrical currents running down her legs." The patient visited her primary care provider, who started a second 30-day treatment of doxycycline (500 $\mathrm{mg}$ twice daily) and gabapentin (900 mg daily before bed).

The patient has been referred to a local physician who has extensive experience with LD for continued management of her medical therapy. At the time of this report, a year later, this patient reports that her symptoms include chronic fatigue and intermittent arthralgia that has required a cane to mobilize at times. Her only medication is methylphenidate (36 mg daily) for fatigue.

\section{Discussion}

The large circular red rash on our patient's back with bull'seye appearance is EM, the characteristic rash of early course LD (Figures 1 and 2). EM begins as a red macule or papule that expands to a large annular area of erythema up to $87 \mathrm{~cm}$ in diameter. ${ }^{10,13,14}$ As the rash border expands, it may leave a partial central clearing. In the US, less than $35 \%$ of patients with EM will demonstrate central clearing. ${ }^{15}$ Less commonly, the center of the rash may appear vesicular or necrotic, as is demonstrated in this case report. ${ }^{16}$ In endemic areas, the presence of EM is considered a reliable indicator of LD. EM arises within 1 month at the tick-bite site, and is present in as many as $70 \%$ of patients. ${ }^{4}$ EM typically improves 
Table 3 Borrelia burgdorferi serologies

\begin{tabular}{|c|c|c|c|}
\hline Day & Parameter & Value & Reference range \\
\hline \multirow[t]{3}{*}{6} & Antibodies to B. burgdorferi, ELISA, ISR & 0.26 & Negative $\leq 0.90$ \\
\hline & & & Equivocal $0.91-1.09$ \\
\hline & & & Positive $\geq 1.10$ \\
\hline \multirow[t]{19}{*}{28} & Antibodies to B. burgdorferi, ELISA, ISR & 5.03 & Negative $\leq 0.90$ \\
\hline & & & Equivocal $0.91-1.09$ \\
\hline & & & Positive $\geq 1.10$ \\
\hline & Quantitative IgM antibodies to B. burgdorferi, & 6.52 & Negative $\leq 0.90$ \\
\hline & ELISA, ISR & & Equivocal $0.91-1.09$ \\
\hline & & & Positive $\geq 1.10$ \\
\hline & IgM antibodies to $B$. burgdorferi, Western blot & Band P23 kD - present & $\lg M$ is considered positive if at least 2 bands \\
\hline & & Band P38 kD - present & are present out of a total of 5 bands \\
\hline & & Band P4I kD - present & \\
\hline & IgG antibodies to $B$. burgdorferi, Western blot & Band PI8 kD - absent & $\lg G$ is considered positive if at least 5 bands \\
\hline & & Band P23 kD - present & are present out of a total of 10 bands \\
\hline & & Band P28 kD - absent & \\
\hline & & Band P30 kD - absent & \\
\hline & & Band P39 kD - absent & \\
\hline & & Band P4I kD - present & \\
\hline & & Band P45 kD - absent & \\
\hline & & Band P58 kD - absent & \\
\hline & & Band P66 kD - absent & \\
\hline & & Band P93 kD - absent & \\
\hline
\end{tabular}

Abbreviations: ELISA, enzyme-linked immunosorbent assay; ISR, immunoglobulin status ratio; Ig, immunoglobulin.

dramatically, and will often resolve following the initiation of appropriate oral antibiotic therapy with either doxycycline or amoxicillin. ${ }^{6}$

LD occurs in stages, with different clinical manifestations that reflect the immune response to B. burgdorferi. ${ }^{4}$ The hallmark of a stage I, early localized infection, is characterized by EM accompanied by systemic viral-like symptoms, including fever, malaise, headache, and joint pain. ${ }^{7,17,18}$ Stage II, early disseminated infection, develops within 1-9 months following an untreated infection, and is due to hematogenous spread of bacteria to sites distant from the original EM lesion. ${ }^{4,16,19}$ Early disseminated infection affects the skin, heart, and the nervous system. ${ }^{16,19}$ Fifty percent of patients develop multiple EM lesions that are typically small and can occur anywhere on the body. ${ }^{4}$ Cardiac involvement is seen in $0.3 \%-4 \%$ of cases, ${ }^{7,20}$ and is usually characterized by varying degrees of transient atrioventricular block. ${ }^{20-23}$ Less than $10 \%$ of untreated patients develop cranial nerve palsy or lymphocytic meningitis., ${ }^{7,424,25}$ Cranial nerve VII is often affected, resulting in unilateral or bilateral facial palsy. Meningitis is associated with episodic headache and mild neck stiffness. Spinal fluid examination may reveal lymphocytic pleocytosis and elevated levels of protein and B. burgdorferi-specific antibody. ${ }^{24-27}$

Stage III, late LD, occurs months to years after the original tick exposure, and includes neurologic manifestations that may progress to encephalopathy, peripheral neuropathy, encephalomyelitis, and arthritic symptoms. ${ }^{28}$ The typical arthritic pattern is monoarticular and oligoarticular arthritis that is chronic relapsing. ${ }^{29}$ Chronic arthritis typically involves one or two large joints, with preference for the knees, and occurs in $11 \%$ of untreated patients with erythema. ${ }^{4,16,30,31}$ On examination, inflamed joints are warm with large effusions. Synovial fluid is inflammatory, with white blood cell counts averaging $24,000 / \mathrm{mm}^{3}$ with a predominance of neutrophils. ${ }^{4,16}$ If untreated, the arthritis may persist or may resolve spontaneously. A few of these patients will have persistent arthritis after antibiotic therapy, and are classified as antibiotic-refractory Lyme arthritis. ${ }^{19}$ Synovial biopsy specimens reveal exaggerated proliferation of synovial tissue, which covers articular cartilage, causing cartilage destruction and permanent deformities. ${ }^{16,20}$ Arthritis of late LD is similar to rheumatoid arthritis, with its characteristic pannus development and consequences., ${ }^{4,32}$

The diagnosis of early LD can be made on the clinical presentation of the classical EM and on a history of known tick bite or probable exposure, considering that serologic testing is too insensitive in the early acute phase of LD. ${ }^{7,33,29}$ Supporting serologic evidence is necessary to secure the diagnosis for disseminated stages. ${ }^{4,33}$ The laboratory diagnosis of LD is rarely based on the microscopic visualization of the Borrelia spirochete in clinical 
samples using polymerase chain reaction assay of biological samples or a culture of the skin biopsy, because these tests are not sensitive enough. ${ }^{3,4,6,10}$

The CDC recommends a two-tier approach for detection of B. burgdorferi-specific antibodies. Detection of IgM antibody, produced during early weeks of LD, can help identify recent infections of B. burgdorferi. IgG antibodies, present $>6$ weeks after onset of illness, rise to higher concentrations than IgM antibodies, and can persist for months or years. ${ }^{34}$ First-generation ELISAs for the detection of anti-Borrelia antibodies lack specificity. The inclusion of a second, more specific, serological method (Western blotting) is used to exclude false-positive ELISA samples. ${ }^{35,36}$

In the ELISA assay, wells of plastic microwell plates are sensitized by passive absorption with $B$. burgdorferi antigen. Test sera from the patient are incubated in antigen-coated microwells. Any antigen-specific antibody in the sample will bind to the antigen coating the well. ${ }^{34,37}$ Peroxidase-conjugated goat antihuman IgM/IgG antibody is added to the wells, and the plate is incubated. The conjugate will react with the human $\operatorname{IgM} / \mathrm{IgG}$ antibody immobilized in the solid phase in step one. ${ }^{34,37,38}$ The microwells containing immobilized peroxidase conjugate are incubated with peroxidase substrate solution. ${ }^{37,38}$ Hydrolysis of the substrate by peroxidase produces a color change. The color intensity of the solution depends on the antibody concentration in the original sample. The color intensity of the solution is measured photometrically, and an optical density value is calculated. Then, an immunoglobulin-status ratio (ISR) is calculated for each specimen by dividing the specimen optical density value by the cutoff optical density value. Only an ISR of $\geq 1.10$ is considered positive. A positive ISR means that antibodies to $B$. burgdorferi are presumptively detected in the serum specimen. . $^{34,-40}$

In Western blotting, an antigen mixture prepared from B. burgdorferi strain B31 is separated by sodium dodecyl sulfate-polyacrylamide gel electrophoresis. ${ }^{41,42}$ B. burgdorferi antigens are then electrophoretically transferred and bound to a nitrocellulose membrane. The patient's serum is then added to the nitrocellulose membrane. If antibodies to B. burgdorferi are present in the serum specimen, they will bind to antigens on the nitrocellulose membrane. ${ }^{42}$ Bands in which a reaction has occurred will be detected by the addition of an enzyme-labeled antihuman $\operatorname{IgG}$ or antihuman $\operatorname{IgM}$ reagent that allows for the visualization of bands on the nitrocellulose membrane. ${ }^{41,42}$ Practically speaking, the test produces something similar to a bar code with several lines or bands. Each band represents antibodies to a different component of the $B$. burgdorferi bacteria. ${ }^{43,44}$ These specific band patterns have been internationally recognized. It is recommended that IgM Western blot is considered positive if at least two bands are present out of a total of five. It is recommended that IgG Western blot is considered positive if at least five bands are present out of a total of ten. ${ }^{38,43-45}$ There has been laboratory variation reported that results in the spread of the sensitivity of the ELISA assay. The sensitivity of the ELISA assay varies from $29 \%-40 \%$ in patients with EM during the acute phase to $28 \%-78 \%$ during the convalescent phase. ${ }^{46-48}$

Early LD and EM are treated with antibiotics on an outpatient basis. Doxycycline (100 mg twice daily by mouth), amoxicillin (500 mg twice a day by mouth), or cefuroxime (250 mg twice a day by mouth) for 10-14 days are equally efficacious. ${ }^{7,4,49}$ Doxycycline is often the drug of choice, because it is also considered the treatment for the Gram-negative bacterium Anaplasma phagocytophilum, a potential tick-borne coinfection. ${ }^{29}$ Macrolides like azithromycin, clarithromycin, and erythromycin should not be selected, due to possible antibiotic resistance that has been identified. ${ }^{50,51}$

Approximately $10 \%-20 \%$ of patients treated for LD with a recommended 2-week course of antibiotics will have lingering symptoms of fatigue, headache, musculoskeletal pain, and lethargy. ${ }^{11}$ Thirty-four percent of a population-based, retrospective cohort study in Massachusetts were found to have arthritis or recurrent arthralgia, neurocognitive impairment, and neuropathy or myelopathy, for a mean of 6 years following treatment for LD. ${ }^{52}$ Sixty-two percent of a cohort of 215 consecutively treated LD patients in Westchester County, New York were found to have arthralgia, arthritis, and cardiac or neurologic involvement for an average of 3.2 years after treatment. ${ }^{53}$ This complication is commonly known as post-treatment LD syndrome (PTLDS). ${ }^{54}$ However, in the absence of additional tests to rule out the eradication of the initial infections, others would argue that the more appropriate diagnosis is chronic LD. ${ }^{55}$

Coinfections are a troubling complication for patients with chronic LD. The reported prevalence of coinfections in the US ranges between $4 \%$ and $28 \%$. In the US, coinfections can include Anaplasma phagocytophilum, which causes human granulocytic anaplasmosis, and babesiosis. ${ }^{56}$ The risk for coinfections is increased, due to the ixodid tick being a vector for all three. ${ }^{56-58}$ Symptoms of a babesiosis infection include fatigue, malaise, weakness, fever $\left(>38^{\circ} \mathrm{C}\right)$, myalgia, arthralgia, and anorexia. ${ }^{56}$ Severe babesiosis infections may progress to acute respiratory distress syndrome, disseminated intravascular coagulation, congestive heart failure, renal failure, myocardial infarction, splenic infarcts or splenic 
rupture, and death. ${ }^{56}$ Records of 139 patients with babesiosis between 1982 and 1993 were analyzed, and nine patients (6.5\%) died, 35 (25.2\%) were admitted to the intensive care unit, and 35 (25.2\%) required hospitalization for more than 14 days. ${ }^{59}$ Rashes in patients with babesiosis are often reflective of concurrent infection with LD. ${ }^{60}$

\section{Conclusion}

We report the case of a patient who presented to a local primary care treatment facility with flu-like symptoms, headache, an expanding EM rash, and later serological studies supporting the diagnosis of LD. Following an antibiotic regimen twice the length and double the recommended treatment dose outlined by the Infectious Diseases Society of America (IDSA), our patient still experiences symptoms of fatigue and arthralgia consistent with PTLDS.

There is a need for diagnostic tests sensitive enough and specific enough for identifying LD in all stages of infection. Some clinicians will find controversy in the diagnosis and treatment of patients presenting with signs and symptoms of LD but lacking any dermatological presentation of the EM rash and presenting with negative serological tests. Current tests may prevent clinicians from being able to diagnose patients accurately who may not have obvious symptoms like EM. Those with clinical presentations distorted by coinfections will also likely experience a delay in their treatment. Clinicians who hesitate to treat patients who do not display all of the diagnostic criteria required by the IDSA may see their patients continue to progress from a subclinical phase to a more advanced phase of LD.

\section{Disclosure}

The authors report no conflicts of interest in this work.

\section{References}

1. Centers for Disease Control and Prevention. Reported cases of Lyme disease by year, United States, 2003-2012. 2013. Available from: http://www.cdc.gov/lyme/stats/chartstables/casesbyyear.html. Accessed November 5, 2013.

2. Meek JI, Roberts CL, Smith EVJR, Cartter ML. Underreporting of Lyme disease by Connecticut physicians, 1992. J Public Health Manag Pract. 1996;2(4):61-65.

3. Stanek G, Wormser GP, Gray J, Strle F. Lyme borreliosis. Lancet. 2012;379(9814):461-473.

4. Bockenstedt LK. Lyme disease. In: Firestein GS, Budd RC, Harris ED Jr, McInnes IB, Ruddy S, Sergent JS, editors. Kelley's Textbook of Rheumatology. 8th ed. Philadelphia: Saunders; 2008.

5. Santino I, Comite P, Gandolfo GM. Borrelia burgdorferi, a great chameleon: know it to recognize it! Neurol Sci. 2010;31(2):193-196.

6. Murray TS, Shapiro ED. Lyme disease. Clin Lab Med. 2010;30(1): 311-328.

7. Meyerhoff JO. Lyme disease. 2013. Available from: http://emedicine. medscape.com/article/330178-overview. Accessed November 5, 2013.
8. Centers for Disease Control and Prevention (CDC). Summary of notifiable diseases - United States, 2010. MMWR Morb Mortal Wkly Rep. 2012;59(53):1-111.

9. Salkeld DJ, Leonhard S, Girard YA, et al. Identifying the reservoir hosts of the Lyme disease spirochete Borrelia burgdorferi in California: the role of the western gray squirrel (Sciurus griseus). Am J Trop Med Hyg. 2008;79(4):535-540.

10. Shapiro ED. Lyme disease. In: Finn A, Pollard AJ, editors. Hot Topics in Infection and Immunity in Children IV. Heidelberg: Springer; 2008:185-195.

11. Centers for Disease Control and Prevention. Lyme disease data. 2013. Available from: http://www.cdc.gov/lyme/stats/index.html. Accessed November 5, 2013.

12. Ullmann AJ, Lane RS, Kurtenbach K, et al. Bacteriolytic activity of selected vertebrate sera for Borrelia burgdorferi sensu stricto and Borrelia bissettii. J Parasitol. 2003;89(6):1256-1257.

13. Smith RP, Schoen RT, Rahn DW, et al. Clinical characteristics and treatment outcome of early Lyme disease in patients with microbiologically confirmed erythema migrans. Ann Intern Med. 2002;136(6):421-428.

14. Mullegger RR. Dermatological manifestations of Lyme borreliosis. Eur J Dermatol. 2004;14(5):296-309.

15. Strle F, Nadelman RB, Cimperman J, et al. Comparison of cultureconfirmed erythema migrans caused by Borrelia burgdorferi sensu stricto in New York State and by Borrelia afzelii in Slovenia. Ann Intern Med. 1999;130(1):32-36.

16. Marques AR. Lyme disease: a review. Curr Allergy Asthma Rep. 2010;10(1):13-20.

17. $\mathrm{Hu}$ LT. In the clinic. Lyme disease. Ann Intern Med. 2012;157(3): ITC2-2-ITC2-16.

18. Esposito S, Bosis S, Sabatini C, Tagliaferri L, Principi N. Borrelia burgdorferi infection and Lyme disease in children. Int $J$ Infect Dis. 2012;17(3):e153-e158.

19. Bhate C, Schwartz RA. Lyme disease: Part I. Advances and perspectives. J Am Acad Dermatol. 2011;64(4):619-636; quiz 637-638.

20. RostoffP, Gajos G, Konduracka E, GackowskiA, Nessler J, Piwowarska W. Lyme carditis: epidemiology, pathophysiology, and clinical features in endemic areas. Int J Cardiol. 2010;144(2):328-333.

21. Sigal LH. Early disseminated Lyme disease: cardiac manifestations. Am J Med. 1995;98(4A):25S-28S; discussion 28S-29S.

22. Naik M, Kim D, O'Brien F, Axel L, Srichai MB. Images in cardiovascular medicine. Lyme carditis. Circulation. 2008;118(18):1881-1884.

23. Hernández-Montfort JA, Awkal M, Martagón-Villamil JA. Looking back at Lyme carditis. Am J Med. 2010;123(6):e9-e10.

24. Halperin JJ. Lyme disease: a multisystem infection that affects the nervous system. Continuum (Minneap Minn). 2012;18(6 Infectious Disease):1338-1350.

25. Biesiada G, Czepiel J, Leśniak MR, Garlicki A, Mach T. Lyme disease: review. Arch Med Sci. 2012;8(6):978-982.

26. Hildenbrand P, Craven DE, Jones R, Nemeskal P. Lyme neuroborreliosis: manifestations of a rapidly emerging zoonosis. AJNR Am JNeuroradiol. 2009;30(6):1079-1087.

27. Rupprecht TA, Koedel U, Fingerle V, Pfister HW. The pathogenesis of Lyme neuroborreliosis: from infection to inflammation. Mol Med. 2008;14(3-4):205-212.

28. Logigian EL, Kaplan RF, Steere AC. Chronic neurologic manifestations of Lyme disease. N Engl J Med. 1990;323(21):1438-1444.

29. Wormser GP, Dattwyler RJ, Shapiro ED, et al. The clinical assessment, treatment, and prevention of Lyme disease, human granulocytic anaplasmosis, and babesiosis: clinical practice guidelines by the Infectious Diseases Society of America. Clin Infect Dis. 2006;43(9):1089-1134.

30. Puius YA, Kalish RA. Lyme arthritis: pathogenesis, clinical presentation, and management. Infect Dis Clin North Am. 2008;22(2):289-300.

31. Steere AC, Malawista SE, Hardin JA, Ruddy S, Askenase W, Andiman WA. Erythema chronicum migrans and Lyme arthritis. The enlarging clinical spectrum. Ann Intern Med. 1977;86(6):685-698.

32. Duray PH. Histopathology of clinical phases of human Lyme disease. Rheum Dis Clin North Am. 1989;15(4):691-710. 
33. Halperin JJ, Baker P, Wormser GP. Common misconceptions about Lyme disease. Am J Med. 2013;126(3):264. e1-e7.

34. Magnarelli LA. Current status of laboratory diagnosis for Lyme disease. Am J Med. April 24, 1995;98(4A):10S-12S.

35. Ang CW, Notermans DW, Hommes M, Simoons-Smit AM, Herremans T. Large differences between test strategies for the detection of anti-Borrelia antibodies are revealed by comparing eight ELISAs and five immunoblots. Eur J Clin Microbiol Infect Dis. 2011;30(8): 1027-1032.

36. Brandenburg AH, van Dam AP, Schellekens J. Problems in comparing test strategies for detection of anti-Borrelia antibodies. Eur J Clin Microbiol Infect Dis. 2011;30(8):1033-1034.

37. Thermo Fisher Scientific. ELISA technical guide and protocols. 2010. Available from: http://www.piercenet.com/files/TR0065-ELISA-guide. pdf. Accessed November 5, 2013.

38. Diagnostic Automation/Cortez Diagnostics. Lyme disease ELISA kit. Available from: http://www.rapidtest.com/index.php?i=Lyme-DiseaseELISA-kit\&id=137\&cat=16. Accessed November 5, 2013.

39. Tilton RC. Laboratory aids for the diagnosis of Borrelia burgdorferi infection. J Spir Tick Borne Dis. 1994;1(1):18-23.

40. Steere AC, McHugh G, Damle N, Sikand VK. Prospective study of serologic tests for Lyme disease. Clin Infect Dis. 2008;47(2): 188-195.

41. Thermo Fisher Scientific. Western Blotting Handbook and Troubleshooting Tools. Version 3. Waltham (MA): Thermo Fisher Scientific. 2013. Available from: http://www.piercenet.com/ Objects $/$ View.cfm? Type=Page $\&$ ID $=03971 E 57-D 4 D 0-4 B 97-971 C$ 0632E8224535. Accessed November 5, 2013.

42. Promega. ECL Western Blotting Substrate: Instructions for use of Products W1001 AND W1015. Fitchburg (WI): Promega. 2009. Available from: http://mcdonald.ucdavis.edu/uploads/1/8/5/3/1853874/ promega_ecl_substrate.pdf. Accessed November 5, 2013.

43. Engstrom SM, Shoop E, Johnson RC. Immunoblot interpretation criteria for serodiagnosis of early Lyme disease. J Clin Microbiol. 1995;33(2):419-427.

44. Kaplan M. Interpreting the IgG and IgM Western blot for Lyme disease.

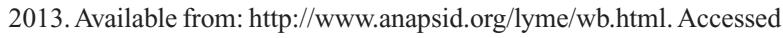
November 5, 2013

45. Devkota BP. Lyme disease serology. 2012. Available from: http:// emedicine.medscape.com/article/2094578-overview\#aw2aab6b2. Accessed November 5, 2013.

46. Aguero-Rosenfeld ME, Nowakowski J, Bittker S, Cooper D, Nadelman RB, Wormser GP. Evolution of the serologic response to Borrelia burgdorferi in treated patients with culture-confirmed erythema migrans. J Clin Microbiol. 1996;34(1):1-9.

47. Nowakowski J, McKenna D, Nadelman RB, et al. Failure of treatment with cephalexin for Lyme disease. Arch Fam Med. 2000;9(6):563-567.
48. Bacon RM, Biggerstaff BJ, Schriefer ME, et al. Serodiagnosis of Lyme disease by kinetic enzyme-linked immunosorbent assay using recombinant VlsE1 or peptide antigens of Borrelia burgdorferi compared with 2-tiered testing using whole-cell lysates. J Infect Dis. 2003;187: $1187-1199$.

49. Girschick HJ, Morbach H, Tappe D. Treatment of Lyme borreliosis. Arthritis Res Ther. 2009;11(6):258.

50. Terekhova D, Sartakova ML, Wormser GP, Schwartz I, Cabello FC. Erythromycin resistance in Borrelia burgdorferi. Antimicrob Agents Chemother. 2002;46(11):3637-3640.

51. Hunfeld KP, Kraiczy P, Kekoukh E, Schäfer V, Brade V. Standardised in vitro susceptibility testing of Borrelia burgdorferi against well-known and newly developed antimicrobial agents - possible implications for new therapeutic approaches to Lyme disease. Int J Med Microbiol. 2002;291 Suppl 33:125-137.

52. Asch ES, Bujak DI, Weiss M, Peterson MG, Weinstein A. Lyme disease: an infectious and postinfectious syndrome. J Rheumatol. 1994;21(3): 454-461.

53. Shadick NA, Phillips CB, Logigian EL, et al. The long-term clinical outcomes of Lyme disease. A population-based retrospective cohort study. Ann Intern Med. 1994;121(8):560-567.

54. Aucott JN, Rebman AW, Crowder LA, Kortte KB. Post-treatment Lyme disease syndrome symptomatology and the impact on life functioning: is there something here? Qual Life Res. 2013;22(1):75-84.

55. Cameron D, Gaito A, Harris N, et al. Evidence-based guidelines for the management of Lyme disease. Expert Rev Anti Infect Ther. 2004;2(Suppl 1):S1-S13.

56. Martínez-Balzano C, Hess M, Malhotra A, Lenox R. Severe babesiosis and Borrelia burgdorferi co-infection. QJM. Epub June 7, 2012.

57. Horowitz HW, Aguero-Rosenfeld ME, Holmgren D, et al. Lyme disease and human granulocytic anaplasmosis coinfection: impact of case definition on coinfection rates and illness severity. Clin Infect Dis. 2013;56(1):93-99.

58. Stricker RB. Counterpoint: long-term antibiotic therapy improves persistent symptoms associated with Lyme disease. Clin Infect Dis. 2007;45(2):149-157.

59. White DJ, Talarico J, Chang H, Birkhead GS, Heimberger T, Morse DL. Human babesiosis in New York State: review of 139 hospitalized cases and analysis of prognostic factors. Arch Intern Med. 1998;158(19): 2149-2154.

60. Krause PJ, McKay K, Thompson CA, et al. Disease-specific diagnosis of coinfecting tickborne zoonoses: babesiosis, human granulocytic ehrlichiosis, and Lyme disease. Clin Infect Dis. 2002;34(9): 1184-1191.
International Medical Case Reports Journal

\section{Publish your work in this journal}

The International Medical Case Reports Journal is an international, peer-reviewed open-access journal publishing original case reports from all medical specialties. Previously unpublished medical posters are also accepted relating to any area of clinical or preclinical science. Submissions should not normally exceed 2,000 words or

\section{Dovepress}

4 published pages including figures, diagrams and references. The manuscript management system is completely online and includes a very quick and fair peer-review system, which is all easy to use. Visit http://www.dovepress.com/testimonials.php to read real quotes from published authors. 